\title{
CÓMO RECUERDO A JOHN MURRA
}

\author{
Ana María Soldi ${ }^{1}$
}

Me crucé en el camino del Dr. John Murra en 1967 y fue en Huánuco donde se iba a realizar un congreso de arte rupestre. Sin tener mucho interés en el tema, había aceptado la invitación de Edmundo Guillén, el entonces Decano de Letras de la Universidad Nacional Hermilio Valdizán, y encontré que en esa pequeña ciudad de temprana fundación española se habían reunido investigadores importantes llegados de Argentina, Chile, México, Colombia; hasta del Norte de África había venido un arqueólogo francés famoso por sus estudios de los petroglifos del Tassili. Se encontraban también etnólogos e historiadores y, aunque no los conocía, no me perdí ninguna de las sesiones y así me empezaron a interesar sus ponencias y las discusiones que seguían.

Durante aquel congreso se presentó un libro recién editado bajo el sello de esa universidad huanuqueña: Visita a la Provincia de León de Huánuco en 1562. No era arqueología sino historia, algo así como el relato de una expedición que debía reconocer unos pueblos y sus habitantes "casa por casa”. Allí estaba el Dr. John Murra diciendo que recientemente unos investigadores habían seguido los pasos del "visitador" y habían identificado algunos de los pueblos nombrados en ese informe de 400 años de antigüedad.

Por otra parte, me enteré que se iban a hacer trabajos arqueológicos en Huánuco Pampa donde se encontraban los restos de un gran centro logístico, administrativo y ceremonial Inca. Sin pensarlo dos veces, me uní a un pequeño grupo de asistentes al congreso, que habían decidido ir a conocer ese lugar y para mí fue una experiencia extraordinaria. A casi 4.000 metros sobre el nivel del mar, a lo largo y ancho de una inmensa planicie se extendían las ruinas y el paisaje era sobrecogedor. Recuerdo que casi me perdí caminando sola entre los muros de piedra, unos casi intactos, otros ruinosos y viendo a lo lejos cientos de depósitos alineados en las faldas de las colinas al filo del horizonte, y en aquel silencio...
Creo que mi evidente curiosidad e interés por todo lo que había visto y escuchado en esos días, además de mi evidente característica exótica en ese medio, fue lo que debió llamarle la atención al Dr. Murra quien al final del congreso conversó conmigo. Quería saber qué hacía allí y a qué había venido esa ítalo-peruana, que por primera vez asistía a un congreso de arqueología. Preguntas difíciles, pero su actitud era amigable y evitando contestar le hablé de la "Visita"que había comenzado a leer, algo tan nuevo para mí. Debo haberle contado que hacía años había conocido algunos arqueólogos, pero que sus actitudes me habían parecido frías cuando se enfrentaban a los materiales que manejaban y sus planteamientos teóricos no me convencían. Por eso estaba contenta de haber encontrado en ese congreso no sólo arqueólogos sino también etnólogos e historiadores y tenía la impresión de que cada uno aportaba algo que podía contribuir a lograr un mejor conocimiento de los seres humanos. En cuanto a esa "Visita" veía que se trataba del relato de una expedición ordenada para reconocer los pueblos que todavía existían, a gente que los había habitado sólo hacía 400 años y con quienes uno casi se podía entender. Sería por eso, por notar mi interés en la historia, que me sugirió buscar a María Rostworowski.

Pasó un tiempo antes de que pudiera encontrarme con Maria, quien estaba entonces en España como Agregada Cultural de nuestra Embajada en Madrid. Mientras tanto, la conversación con John, iniciada al final del congreso huanuqueño, se había reanudado por correspondencia. Él enseñaba, viajaba mucho y seguía preocupado por la segunda parte de la "Visita" cuyo texto aún no había sido publicado por diversas razones. Durante una de sus breves estadías en Lima me convenció para que colaborara con la realización de esta empresa, y así fue como poco a poco me estuve involucrando en las diferentes tareas que requería la publicación del Segundo Tomo de la Visita que llegó a los lectores en 1972 y que comprende el ensayo fundamental de

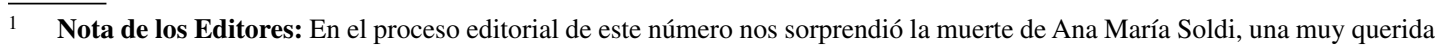
amiga y colega del Dr. Murra. 
John Murra: El "control vertical" de un máximo de pisos ecológicos en la economía de las sociedades andinas".

Esta experiencia y la responsabilidad compartida me habían permitido conocer a colegas y alumnos de John, algunos de ellos ya activos en la enseñanza y la investigación de la arqueología, la antropología y la historia andina. Terminada la empresa editorial, el profesor Murra insistía diciéndome que ya debía comenzar a dedicarme a algo mío en serio: leer, estudiar, escoger un área y un tema al cual dedicarme personalmente. Sabía de mi anterior formación en las ciencias humanas, pero el reto era difícil de aceptar ya que me pedía que si quería dedicarme a lo andino, antes debía conocer acerca de otros mundos y otras culturas y tratar así de percibir las coincidencias y las diferencias. Debía leer acerca de los reinos africanos, los esquimales, la Melanesia... leer a Boas, Benedict, Malinowski, Firth (jestábamos en la década de 1970!) y eso era demasiado, aunque poco a poco fui leyendo y aprendiendo lo suficiente como para saber que lo que debía proponerme era conocer y entender el mundo andino que estaba a mi alcance.

John siempre me había puesto como modelo a seguir a Maria Rostworowski. La admiraba y estaba seguro que me ayudaría y así fue, porque desde que la conocí y durante los años que siguieron, llegué a apreciar cada vez más su generosidad, su talento, su lucidez, su dedicación al estudio y nuestra amistad ahorráoslo se fue enriqueciendo con el tiempo, hasta hoy. De vez en cuando salíamos al campo con un documento a la mano para reconocer el terreno, verificar toponimias, ubicar los restos de algunas estructuras significativas, y con suerte a veces encontrábamos algún viejo poblador que nos podía ser de ayuda con sus recuerdos. ¡Cuánto aprendí de María y con ella!

Ahora se trataba de elegir un tema entre tantos y creo que no fue difícil. Por años había vivido en una zona desértica de la costa centro-sur del Perú donde se encontraban vestigios de antiguos asentamientos humanos y era evidente que, a pesar de las condiciones adversas del medio, allí hubo algún tipo de agricultura. Buscar dónde existían afloramientos de agua, constatar cómo habían sido aprovechados y de qué manera se utilizaron esos escasos recursos, fue el principio de una aventura apasionante. Primero en el terreno y luego en los archivos fui encontrando la evidencia de que allí los indígenas locales habían practicado antiguamente algún tipo de agricultura muy peculiar y que los invasores españoles la habían adoptado y la siguieron practicando con éxito hasta mitad del siglo XX. Si algo he podido aportar al conocimiento y al estudio de la agricultura tradicional en el desierto, se lo debo a John Murra quien desde el principio aprobó y alentó mi iniciativa.

En esos años John me habló de otro tema del todo ajeno a mis actividades del momento: se trataba de entrevistar al Dr. Luis E. Valcárcel y grabar los recuerdos de sus años juveniles en el Cusco, antes y durante sus primeros años de maestro e investigador de la arqueología local. Cuando me lo propuso, la idea me desconcertó ya que no conocía al personaje y no tenía experiencia de reportera... pero John sabía convencer. Consultado previamente, el Dr. Valcárcel me recibió de manera muy cordial y tuve la impresión de que la idea le gustaba. Siguieron numerosas visitas semanales y la conversación se fue haciendo más y más interesante y amena. Su mente era muy lúcida y su memoria le permitía volver atrás recordando lugares, personas, acontecimientos. John me ofreció así el privilegio de conocer de cerca a una persona que de otra manera no habría podido conocer y apreciar en todo su valor intelectual y humano.

No conocí personalmente a José María Arguedas. Algo había leído de él, algo sabía de su vida y mucho más lo llegué a conocer a través de John. Los unía una profunda amistad y compartían una apasionada dedicación por el mundo andino en todas sus manifestaciones. Arguedas lo vivió, lo sufrió, lo gozó siempre exaltándolo hasta el final. John lo reconoció desde temprano y lo asumió como suyo. Una vez me escribió: "Las ideas que estoy impulsando en la antropología andina forman parte vital de lo que quiero no sólo hacer sino ser" (el subrayado es suyo).

John había pensado editar una publicación que se llamaría ÑISPA ÑINKU, "Una carta circular de las investigaciones andinas en curso". En 1970, un año después de la muerte de Arguedas, estaba listo el primer número dedicado a su entrañable amigo y que se abría con el poema "Llamado a algunos doctores" en el texto original quechua y su traducción por el mismo autor. El poema estaba dedicado a Carlos Cueto Fernandini y a John Murra.

Desde muy temprano John rechazó lo que para él significaba "familia" y "lazos familiares", los que trató de desatar temprano para no comprometerse con algo que él percibía como una obligación. No había 
cumplido 21 años cuando aceptó un compromiso mucho mayor, la Guerra Civil Española, una causa que lo atrajo, lo involucró y por último lo decepcionó, no tanto por la causa en sí ni por su fracaso, sino porque en un sentido había traicionado sus propias ilusiones y su entrega... "Es un capítulo cerrado, pero jamás se cierra"... Por otra parte, tratando de explicar lo que para él era "familia", una vez me escribió: "...no fue sino en el ejército republicano que me di cuenta que uno podía amar a otros, no por obligación sino porque así lo sentía”.

Hace años en Barcelona me pidió que lo acompañara a hacer un recorrido por donde lo llevara la memoria y encontramos en Mataró el hospital donde lo habían llevado herido y donde estuvo convaleciendo y aprendiendo nuevamente a caminar. Aunque no quiso volver a verla, me hablaba de la gran playa de Argelés, al otro lado de la frontera con Francia donde junto con él habían sido concentrados cientos de los combatientes derrotados de "nuestra guerra". Allí, desde América, fue a visitarlo su madre.

John siempre trataba de evitar las reuniones que de vez en cuando organizaban los "brigadistas" y cuando aceptaba algunas invitaciones, los recuerdos no eran buenos. Uno de los camaradas de la guerra con quien mantuvo una relación muy larga fue el psicoanalista Saul Newton: "Oficial del Batallón 60, 15 Brigada, Ejercito Republicano Español”. Ante la sorpresa de muchos, John le dedicó su tesis doctoral ya que siempre dijo y escribió que sin su ayuda nunca habría podido terminarla.

Entre los que John llamaba "mis amigos de la guerra", ocupaba un lugar muy especial Ángel Palerm, de origen español, exiliado en México tras la guerra y eminente antropólogo. Las relaciones profesionales y personales con él y su esposa fueron muy estrechas y duraron 40 años, hasta la muerte de Ángel. Creo que para él eran "familia".

Podemos reconocer las huellas que dejó el maestro John Murra en los que fueron sus alumnos y después colegas. Entre los que he conocido, admiro en especial a Heather Lechtman, alumna fiel quien muy, muy joven mecanografió el manuscrito de la tesis de su maestro y ahora transmite a sus alumnos las enseñanzas que recibió de él. Craig Morris quien, atraído por la lectura de la tesis de John Murra, dejó por un tiempo los estudios en Chicago para ir a trabajar como arqueólogo voluntario en Huánuco Pampa. John reconocía y admiraba en él muchos talentos. Para mí, Craig fue un gran amigo, antes y durante los años en que trabajé con él en otro proyecto arqueológico. John Hyslop fue otro buen amigo quien, inspirado por John Murra, dedicó años de su juventud a reconocer en el terreno, recorrer y registrar tramos de los caminos Inca y animar a otros para que continuaran con el trabajo que él no pudo terminar.

A John le debo el haber tenido la oportunidad de conocer, querer y admirar a muchas personas que en el transcurso de tantos años han enriquecido mi vida.

Quienes hemos encontrado a John en algún momento de nuestras vidas y lo hemos seguido a lo largo de los años, decimos que lo hemos conocido, pero, ¿cuáles y cuántas de las innumerables facetas de una personalidad tan compleja permanecen en nuestra memoria? Fiel a sus principios, inconforme, imprevisible, a veces cercano, a veces inaccesible. Él mismo me escribía: "el fulano desconocido que vive en mî”.

Más allá del mundo andino, que desde que lo descubrió tuvo un lugar privilegiado en su mente y en sus preocupaciones, John compartía de cerca o de lejos la suerte de otras, personas, instituciones, países. El correo era su inquietud constante. "¿Qué haremos si el correo sigue deteriorándose?... tanto de mi vida depende del correo..".. Durante sus innumerables viajes escribía desde cualquier lugar donde se encontraba: aeropuertos, aviones, hasta durante las sesiones del algún congreso, haciendo comentarios a veces con sarcasmo e ironía, a veces de manera burlona cuando algo lo divertía o lo aburría.

Para mí eran muy buenos los momentos en que podíamos trabajar juntos en algo que lo preocupaba en ese momento, desde revisar con cuidado algún manuscrito suyo reciente, hasta cuando se cansaba y buscaba pretextos para volver a escribir una parte o todo. En otras ocasiones y ya de lejos, eran los comentarios de alguna obra de autores que conocíamos y compartíamos: ensayos, novelas, biografías, poemas; a veces coincidiendo, otras veces discrepando.

Cuando me escribía en los días oscuros afloraba el desaliento: “¿Qué puede hacer un hombre, sólo con todos sus talentos, papel y una pluma contra el desorden del mundo?" El mismo John pocos días después me escribía: "me gusta la idea de saber manejar. Es tan increíble que he aprendido esto y aunque lo hago mediocremente, el milagro es tal que es una satisfacción continua". Esto le permitía hacer viajes cortos a Boston, a Montreal... y hasta cultivó, no sé cuán seriamente, la idea de ir 
manejando hasta México con ocasión de una larga reunión que hubo allí en 1972.

Era muy sensible al cambio de las estaciones: el esplendor otoñal del follaje con todos los matices de rojo, un privilegio de las regiones del Norte, lo admiraba pero con una sutil melancolía, como el preludio del largo invierno que se estaba anunciando. Lo deprimía el invierno pero le levantaba el ánimo percibir los primeros asomos de la primavera en Ithaca, cuando descubría las florcitas azules que asomaban entre las últimas nieves, mientras ya en abril, admiraba con maravilla la trashumancia estacional de las grandes ánades canadienses que por miles y a veces en formación cerrada cruzaban el cielo rumbo al norte. También era motivo de alegría cuando, al regresar a casa después de alguno de esos viajes agotadores, encontraba que en su jardín estaban floreciendo las peonías y que las cerezas estaban madurando en el árbol nuevo que había remplazado el antiguo cerezo que tuvo que ser sacrificado.

Estos y otros momentos de descanso, de paz consigo mismo y con el mundo, son los que quiero recordar de mi gran amigo John. 